\title{
Secretion and Degradation of Mutant Leucine-Specific Binding Protein Molecules Containing C-terminal Deletions
}

\author{
Robert Landick, James R. Duncan, Bruce R. Copeland, Penelope M. Nazos, \\ and Dale L. Oxender \\ Department of Biological Chemistry, University of Michigan Medical School, Ann Arbor, \\ Michigan 48109
}

\begin{abstract}
The leucine-specific binding protein (LS-BP), a periplasmic component of the Escherichia coli high-affinity leucine transport system, is initially synthesized in a precursor form with a 23 amino acid $\mathrm{N}$-terminal leader sequence that is removed during secretion of the protein into the periplasm. Using in vitro mutagenesis, deletion mutants of the LS-BP gene have been constructed with altered or missing amino acid sequences in the C-terminal portion of the protein. These altered binding proteins exhibited normal processing and secretion but were rapidly degraded in the periplasmic space. In the presence of an uncoupler of the transmembrane potential (CCCP) the precursor forms accumulated in the membrane and were protected from degradation. The altered binding proteins also were secreted by spheroplasts of $E$ coli, after which they were easily detected.
\end{abstract}

Key words: leucine binding protein, protein secretion, proteolysis, degradation, site-directed mutagenesis, membrane potential, processing, periplasmic proteins

Escherichia coli, like other gram-negative bacteria, contains a periplasmic space between its inner and outer membranes. This periplasmic space contains several types of proteins, such as nutrient-binding proteins [1-4] and hydrolytic enzymes [5,6], that must be translocated across the inner membrane. Periplasmic proteins are synthesized as precursors with 20-25 amino acid N-terminal extensions [2,7]. This signal se-

\footnotetext{
Abbreviations used: CCCP, carbonylcyanide-m-chlorophenylhydrazone; EDTA, ethylenediaminetetraacetic acid; LIV-BP, leucine, isoleucine, valine-binding protein; LS-BP, leucine-specific binding protein; MW, molecular weight; SDS, sodium dodecyl sulfate.
}

Robert Landick is now at Department of Biological Sciences, Stanford University, Stanford, CA 94305.

James R. Duncan is now at School of Medicine, Washington University, St. Louis, MO 63110.

Received October 4, 1983; accepted January 13, 1984. 


\section{2:JCB Landick et al}

quence is removed by proteolytic processing by a leader peptidase $[8,9]$ during the secretory process. The processing step can be blocked by treating cells with ionophores such as carbonylcyanide-m-chlorophenylhydrazone (CCCP) or valinomycin [10-13]. Inhibition of processing prevents release of the unprocessed proteins into the periplasm [10].

We have studied the leucine-specific binding protein (LS-BP), a periplasmic component of the high-affinity leucine transport system [14-16], as a model for periplasmic protein secretion. For these studies we have constructed mutant LS-BP genes that contain deletions near the $3^{\prime}$ end of the gene and therefore code for LS-BP molecules with altered or missing amino acid sequences near their C-termini. To construct these deletions we cleaved plasmid pOX7 [16] at a unique Bam $\mathrm{HI}$ site equivalent to amino acid 254 of the mature LS-BP and removed varying amounts of the gene with the double-stranded exonuclease BAL-31 [17]. After transforming the $E$ coli recA strain AEA04 with the religated plasmid we analyzed the structure of many clones and chose three for further experimentation. One plasmid, pOX $7 \Delta B 14$, coded for a LS-BP molecule (LS-BP $\Delta$ B14) that was missing 234 nucleotides around the Bam HI site (78 amino acids) and was fused so that the remaining portion of LS$\mathrm{BP} \triangle \mathrm{B} 14$ was translated in the correct reading frame. The other two plasmids, pOX $7 \Delta \mathrm{C} 16$ and pOX7 $7 \mathrm{G} 13$, had smaller deletions around the Bam HI site, but coded for truncated proteins due to fusion out of frame.

In this report we (1) describe the structural analysis of LS-BP $\Delta B 14$, LS$\mathrm{BP} \Delta \mathrm{C} 16$, and LS-BP $\Delta \mathrm{G} 13$, (2) demonstrate that all three altered proteins are secreted in spheroplasts of E coli, and (3) show that these altered LS-BP molecules are degraded by periplasmic proteases so that secreted forms are not stable in the periplasm. Finally, we discuss the implications of these results for experimental strategies designed to secrete ordinarily nonsecretory proteins.

\section{EXPERIMENTAL PROCEDURES}

\section{Materials}

CCCP was purchased from Sigma Chemical Company; $\left[{ }^{35}\right.$ S $]$ methionine $(>800$ $\mathrm{Ci} /$ mmole), from New England Nuclear; T4 DNA ligase, from New England Biolabs; restriction enzymes and BAL-31 nuclease, from Bethesda Research Labs, Inc; and goat antirabbit IgG antisera, from Miles. Rabbit antisera against the LIV-BP was prepared by conventional methods and was previously found to be cross-reactive with the LS-BP [18]. E coli strain AE404 (livH, livR, argG6, his-1, trp-31, recA, pdxC, mtl-2, xyl-7, malA1, gal-6, lacZ4, str-104, tonA2, tsx-1, supE44) was constructed by standard genetic techniques from the E coli Genetic Stock Center (New Haven, CT 06510) strain CGSC 4273. The construction of plasmid pOX7 has been described [16].

\section{DNA Methods}

Plasmid DNA was prepared by the cleared lysate procedure of Clewell and Helinski [19] and purified by buoyant density centrifugation in ethidium bromide/ $\mathrm{CsCl}$ gradients. All restriction enzyme digestions were conducted under the conditions recommended by the supplier. Transformation of $\mathrm{E}$ coli was performed as previously described [20]. DNA sequencing was performed as described by Maxam and Gilbert [21]. 


\section{Assays for Synthesis, Processing, and Secretion of Plasmid-Coded Proteins}

Plasmid-bearing cells to be assayed for synthesis and processing of secretory proteins were grown in $10 \mathrm{ml}$ of 4-morpholine propanesulfonic acid (MOPS)-rich medium [22] without leucine and containing $20 \mu \mathrm{g} / \mathrm{ml}$ ampicillin to an $\mathrm{OD}_{600}$ of 0.8 . Treatment of cells for the assay of CCCP inhibition of secretory protein processing and for the assay of secretory protein secretion of spheroplasts was done as previously described $[10,13,23]$.

Assays for protein synthesis and secretion in spheroplasts were conducted essentially as described $[10,13,23]$. Briefly, cells containing recombinant plasmids were grown in either MOPS-rich medium without leucine or MOPS-minimal medium with appropriate supplements and then treated with lysozyme-EDTA in $0.75 \mathrm{M}$ sucrose, $10 \mathrm{mM}$ TRIS-HCl, $\mathrm{pH} 8.0$, on ice. After addition of DNase, the spheroplasts were pelleted by centrifugation at $10,000 \mathrm{~g}$ for $15 \mathrm{~min}$. The spheroplasts were resuspended in MOPS-rich medium containing $12 \%$ sucrose and lacking methionine. The spheroplasts were labeled with $\mathrm{L}-\left[{ }^{35} \mathrm{~S}\right]$ methionine at $37^{\circ} \mathrm{C}$ for $20-30 \mathrm{~min}$ and then centrifuged at $12,000 \mathrm{~g}$ for $10 \mathrm{~min}$ to separate the spheroplasts from the labeling medium. The fractions were separately immunoprecipitated as previously described [13] and analyzed by SDS polyacrylamide gel electrophoresis.

\section{Protein Electrophoresis}

SDS polyacrylamide gel electrophoresis was conducted as described by Laemmli [24] in $11 \%$ acrylamide gels containing $0.4 \%$ bisacrylamide. When the bromphenol blue dye marker reached the bottom of the gel, the gel was removed from the electrophoresis apparatus, fixed in $30 \%$ methanol, $10 \%$ acetic acid in water and treated with Enhance (New England Nuclear) according to the manufacturer's instruc tions. The gels were dried and placed against Kodak X-Omat AR-5 film at $-70^{\circ} \mathrm{C}$ for autoradiography.

\section{Construction of LS-BP Deletions}

Plasmid pOX7 [16], which contains a unique Bam HI site at codon 277 of the LS-BP gene (codon 254 of the portion of the gene coding for the mature protein), was treated with Bam $\mathrm{HI}$ and the linear plasmid was purified by electrophoresis

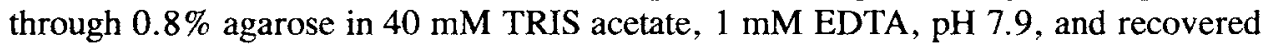
by electroelution in dialysis tubing; $2 \mu \mathrm{g}$ of the purified, Bam HI-cut plasmid was treated with 0.5 units $/ \mathrm{ml}$ of the double-stranded exodeoxyribonuclease BAL-31 [17] in $20 \mu \mathrm{l}$ of $600 \mathrm{mM} \mathrm{NaCl}, 12 \mathrm{mM} \mathrm{MgCl}_{2}, 12 \mathrm{mM} \mathrm{CaCl}, 1 \mathrm{mM}$ EDTA, $20 \mathrm{mM}$ TRIS $\mathrm{HCl}, \mathrm{pH} 8.1$, for $2 \mathrm{~min}$ at $37^{\circ} \mathrm{C}$. The reaction was stopped by addition of $50 \mu \mathrm{l}$ of phenol and $200 \mu \mathrm{l}$ of $0.3 \mathrm{M}$ ammonium acetate. The aqueous phase was recovered after centrifugation at $4^{\circ} \mathrm{C}, 10,000 \mathrm{~g}$, for $10 \mathrm{~min}$ and extracted twice with diethyl ether. After precipitation by addition of 2.5 volumes of ethanol, the DNA pellet was washed with $75 \%$ ethanol, dried in vacuo, and redissolved in $30 \mu \mathrm{l}$ of ligase buffer; 450 units of T4 DNA ligase were added and the mixture was incubated at $16^{\circ} \mathrm{C}$ for $16 \mathrm{hr}$. The reaction mixture was used to transform E coli strain AE 404 to ampicillin resistance; 180 resistant colonies were screened for the presence of a plasmid missing the Bam $\mathrm{HI}$ site. Of ten plasmids that contained small deletions around the Bam HI site, three ( $\mathrm{pOX} 7 \Delta \mathrm{B} 14$, $\mathrm{pOX} 7 \Delta \mathrm{C} 16$, and $\mathrm{pOX} 7 \Delta \mathrm{G} 13$ ) were chosen for further characterization. 


\section{RESULTS}

\section{Structural Analysis of the LS-BP Deletions}

Figure 1 shows restriction enzyme mapping data for plasmids pOX7 $\Delta \mathrm{B} 14$, pOX $7 \Delta \mathrm{C} 16$, pOX $7 \Delta \mathrm{G} 13$, and pOX7. Based on the Hinf I digestion patterns, the B14 deletion was approximately 235 base pairs, the G13 deletion was approximately 196 base pairs, and the C16 deletion was approximately 138 base pairs. Knowledge of the exact location of Taq I restriction enzyme recognition sites from the DNA sequence of the LS-BP gene [R. Landick and D.L. Oxender, manuscript in preparation], allowed us to define the approximate endpoints of the three deletions as shown in Figure 2. All three of the deletions remove the first Taq I site upstream from the Bam HI site as evidenced by the absence of the 120-base-pair Taq I fragment (see Fig. 1). Since the 742 base-pair fragment at the $5^{\prime}$ end of the LS-BP gene is undisturbed in all three deletions, we concluded that the $5^{\prime}$ end of each deletion was in the 66-base-pair Taq I fragment. Since the size of each deletion based on the Taq I digestion was larger than the size deduced from the Hinf I digestion pattern, we concluded that the $5^{\prime}$ end of the deletions must be near the $3^{\prime}$ end of the 66-base Taq I fragment, so that, in the deletions, this fragment was fused to the large Taq I fragment $3^{\prime}$ to the Bam HI site. Therefore, beginning around amino acid 230 of the mature LS-BP, the B14 deletion removed about 75 amino acids; the G13 deletion, about 65 amino acids; and the C16 deletion, about 46 amino acids.

\section{Synthesis and Secretion of the LS-BP Deletion Proteins in Spheroplasts}

To confirm that these three plasmids produced a deleted protein and to find out if the proper reading frame was conserved, it was necessary to examine the proteins synthesized by these plasmids. We tried several techniques, including coupled in vitro transcription/translation, whole cell labeling, and spheroplast labeling to detect synthesis of the LS-BP deletion proteins. Both in vitro transcription/translation and whole cell labeling gave nonreproducible synthesis of the deletion proteins; it appeared that they were being proteolytically degraded in these experiments (see Fig. 4 and results below). As shown in Figure 3A, however, all three deletion proteins were easily detected by $\left[{ }^{35}\right.$ S]methionine labeling of spheroplasts. All three deletion proteins were found in the labeling media, indicating that they were secreted through the cytoplasmic membrane. Control experiments (data not shown) verified that only normally secreted proteins were found in the labeling medium using this protocol and the bulk of the labeled proteins were retained in the spheroplast pellet. Interestingly, it was apparent from the sizes of the three deletion proteins based on the MW standards (Fig. 3A) that only the LS-BP $\triangle B 14$ was fused in the correct reading frames. Based on the DNA mapping data shown in Figures 1 and 2, both the pOX7 $\Delta \mathrm{C} 16$ and pOX $7 \Delta$ G13 plasmids contained smaller deletions than the pOX $7 \Delta B 14$ plasmid, yet the protein products LS-BP $\Delta$ G13 and LS-BP $\Delta$ C16 were both smaller than LS$\mathrm{BP} \Delta \mathrm{B} 14$. Therefore, we concluded that both LS-BP $\Delta 13$ and LS-BP $\Delta \mathrm{C} 16$ were fused out of frame and produced truncated proteins. To verify that the three deletion proteins were processed as well as secreted we ran samples of $\left[{ }^{35} \mathrm{~S}\right]$ methionine-labeled, CCCP-

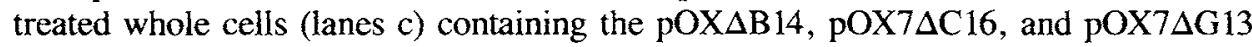
plasmids on the gel whose autoradiograph is shown in Figure 3B. These conditions produced the precursors of the deleted LS-PBs and it was clear that the proteins secreted in spheroplasts (lanes s) were indeed processed. We did observe that the G13 


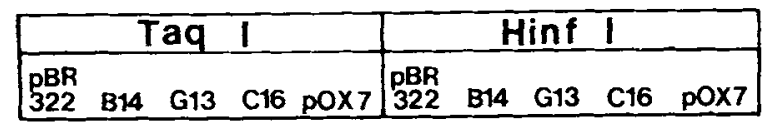

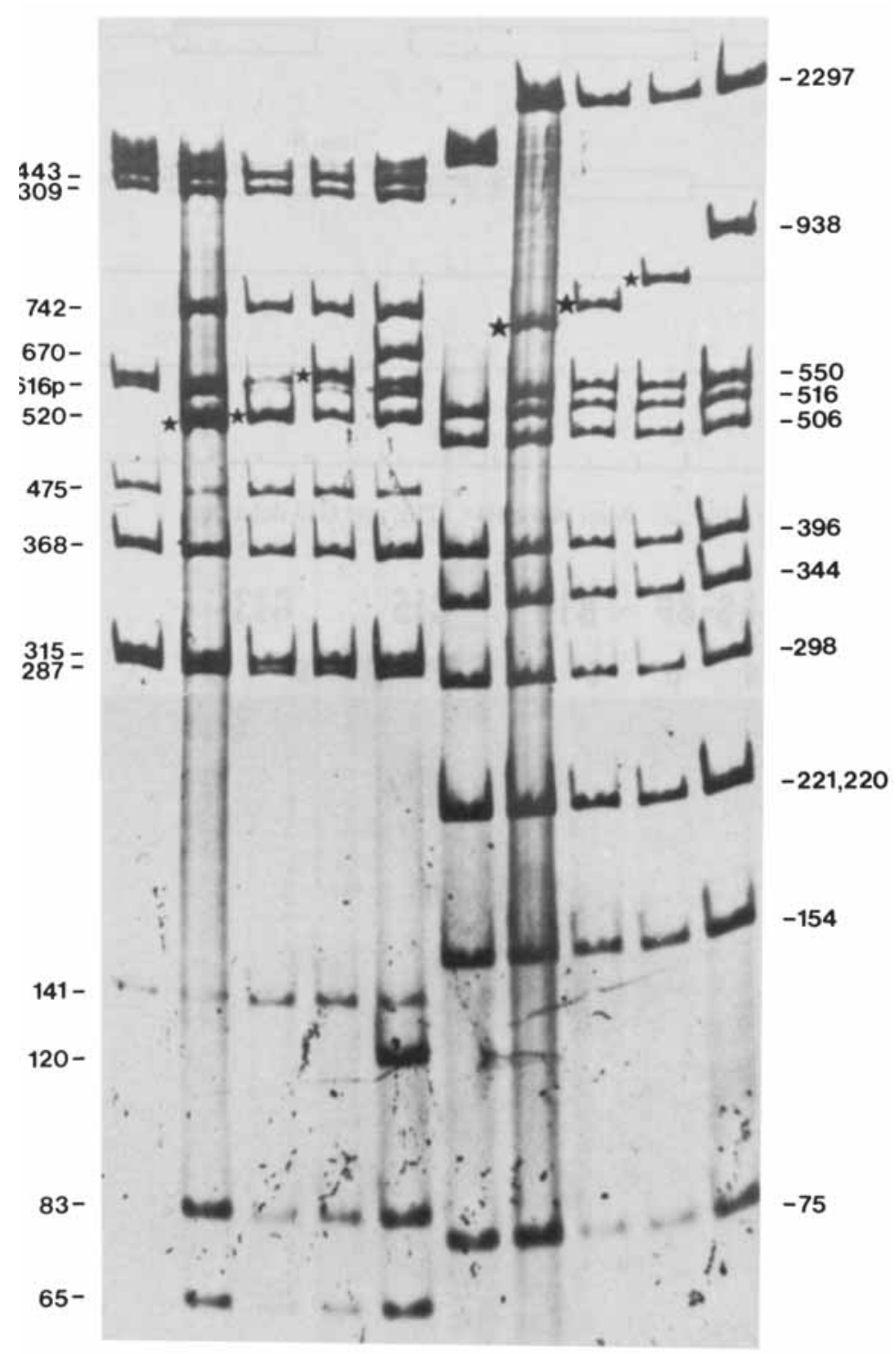

Fig. 1. Gel electrophoresis patterns of restriction endonuclease digestions of pOX7, pOX7 deletions, and pBR322. The stars mark the fragments that are affected by the deletions. The numbers on the left and right of the figure refer to the known sizes in base pairs of the corresponding DNA fragments based on the DNA sequence of pBR322 [29] and pOX7 [Landick and Oxender, manuscript in preparation]. The band labeled $616 \mathrm{p}$ results from partial digestion of the Taq $I$ recognition site at position 1126 of pBR322 [29] which is partially protected from cleavage by methylation. 


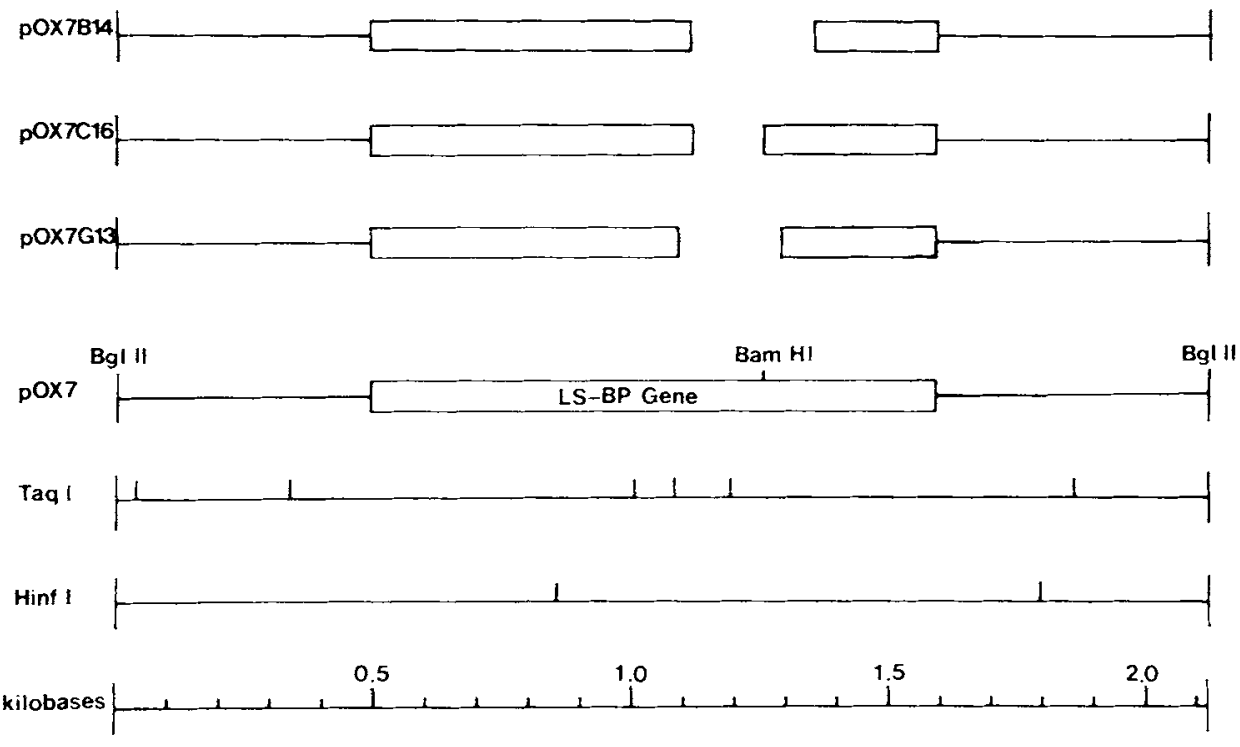

Fig. 2. Map of the B14, C16, and G13 deletions.

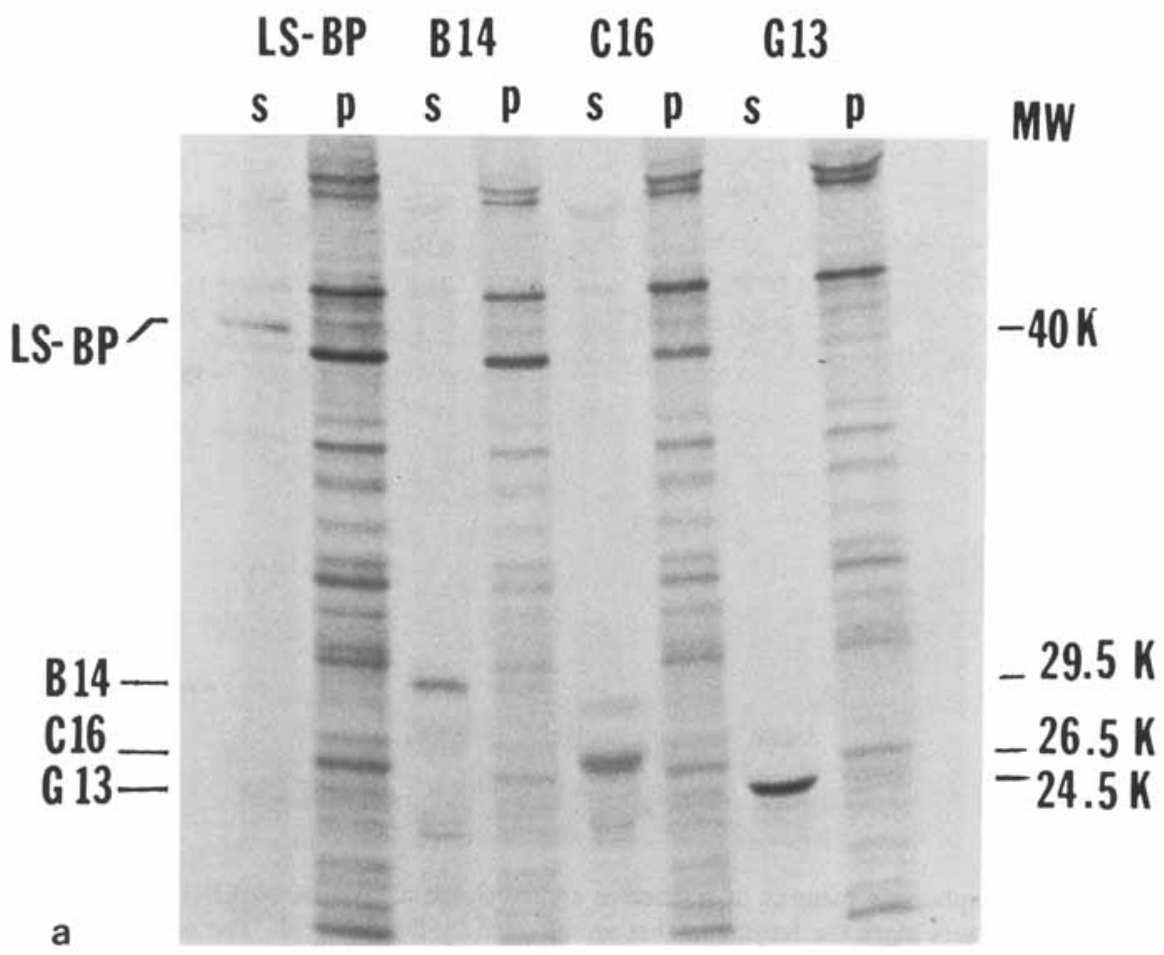

Fig. 3. Synthesis and secretion of LS-BPAB14, LS-BP $\Delta$ C16, and LS-BP $\Delta$ G13 in spheroplasts. a)

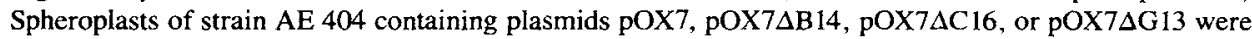
prepared as described in Experimental Procedures. The spheroplasts were suspended in MOPS-rich medium without methionine or leucine and labeled by addition of $10 \mu \mathrm{Ci}$ of $\left[{ }^{35} \mathrm{~S}\right]$ methionine and incubation at $37^{\circ} \mathrm{C}$ for $30 \mathrm{~min}$. Spheroplasts were removed by centrifugation at $12,000 \mathrm{~g}$ for $10 \mathrm{~min}$ and the supernatant fluid [lanes s, (a)] and pellet fractions [lanes $p,(a)$ ] were prepared for immunoprecipita- 
and C16 deletion proteins tended to produce more than one band in the spheroplast labeling experiment. In each case, the top band was consistent with the removal of the 23-amino-acid signal sequence and we attributed the lower bands to partial proteolytic degradation of LS-BP $\Delta$ G13 and LS-BP $\Delta$ C 16. In separate experiments (not shown) we observed much more extensive proteolysis of the deletion proteins when the spheroplast labeling was terminated by addition of excess unlabeled methionine. Presumably, this allowed synthesis and secretion of sufficient periplasmic proteases to cause the increased degradation.

\section{Synthesis and Degradation of LS-BP Deletion Proteins in Whole Cells}

We also examined processing and looked for secretion of the deletion proteins in intact cells. We treated AE 404/pOX7, AE 404/pOX7 BB14, AE 404/pOX7 $\Delta \mathrm{C} 16$, and $A E 404 / p O X 7 \triangle G 13$ as described in Experimental Procedures to assay for protein synthesis and processing. As shown in Figure 4A, we examined synthesis of LS$\mathrm{BP} \triangle \mathrm{B} 14$ and LS-BP after $0,10,32$, and $100 \mu \mathrm{M}$ CCCP treatment of cells. A band corresponding to LS-BP $\triangle \mathrm{B} 14$ was evident in anti-LIV-BP immunoprecipitation of

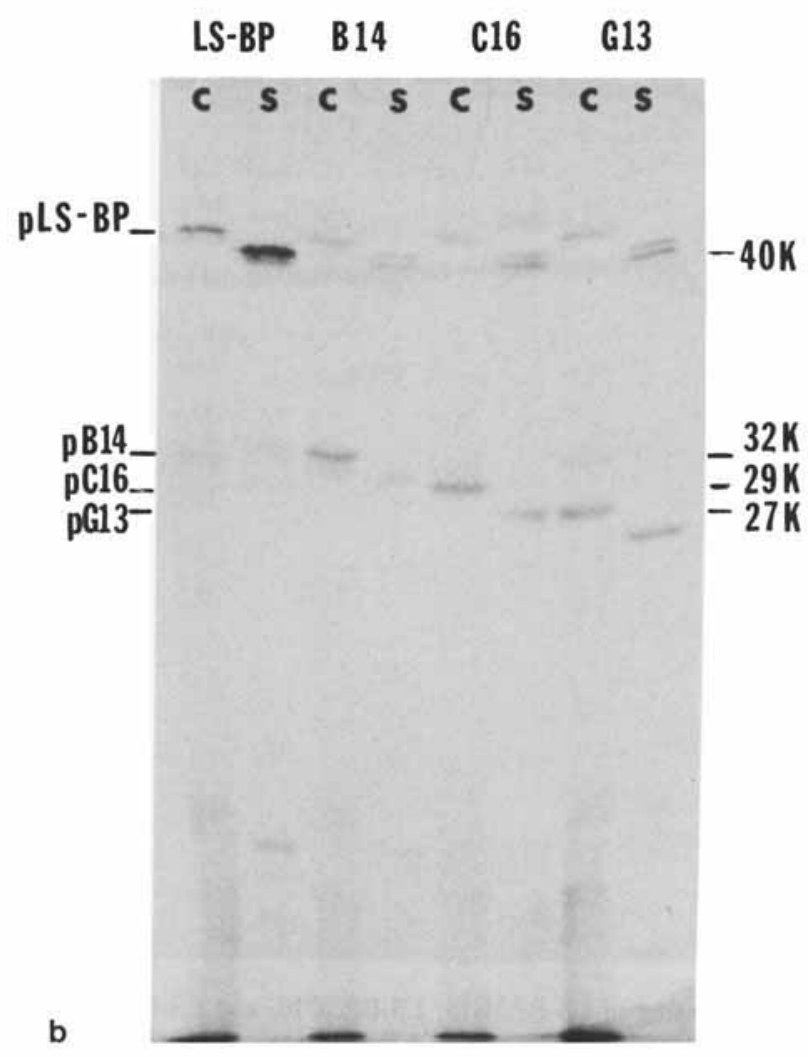

Fig. 3 (continued)

tion and electrophoresis as previously described [13]. b) The lanes labeled c refer to samples from CCCP-treated whole cells of $\mathrm{AE} 404$ containing pOX $7 \Delta \mathrm{B} 14$, pOX $7 \Delta \mathrm{C} 16$, or pOX $7 \Delta \mathrm{G} 13$ as described in the legend to Figure 4 . The lanes labeled s correspond to samples of supernatant of spheroplasts from the cells indicated. The multiple bands seen in the C16 and G13 deletions are presumed to arise from partial degradation of the deletion proteins (see text). In each case, the uppermost band is the appropriate size for the processed form of the deleted proteins. 


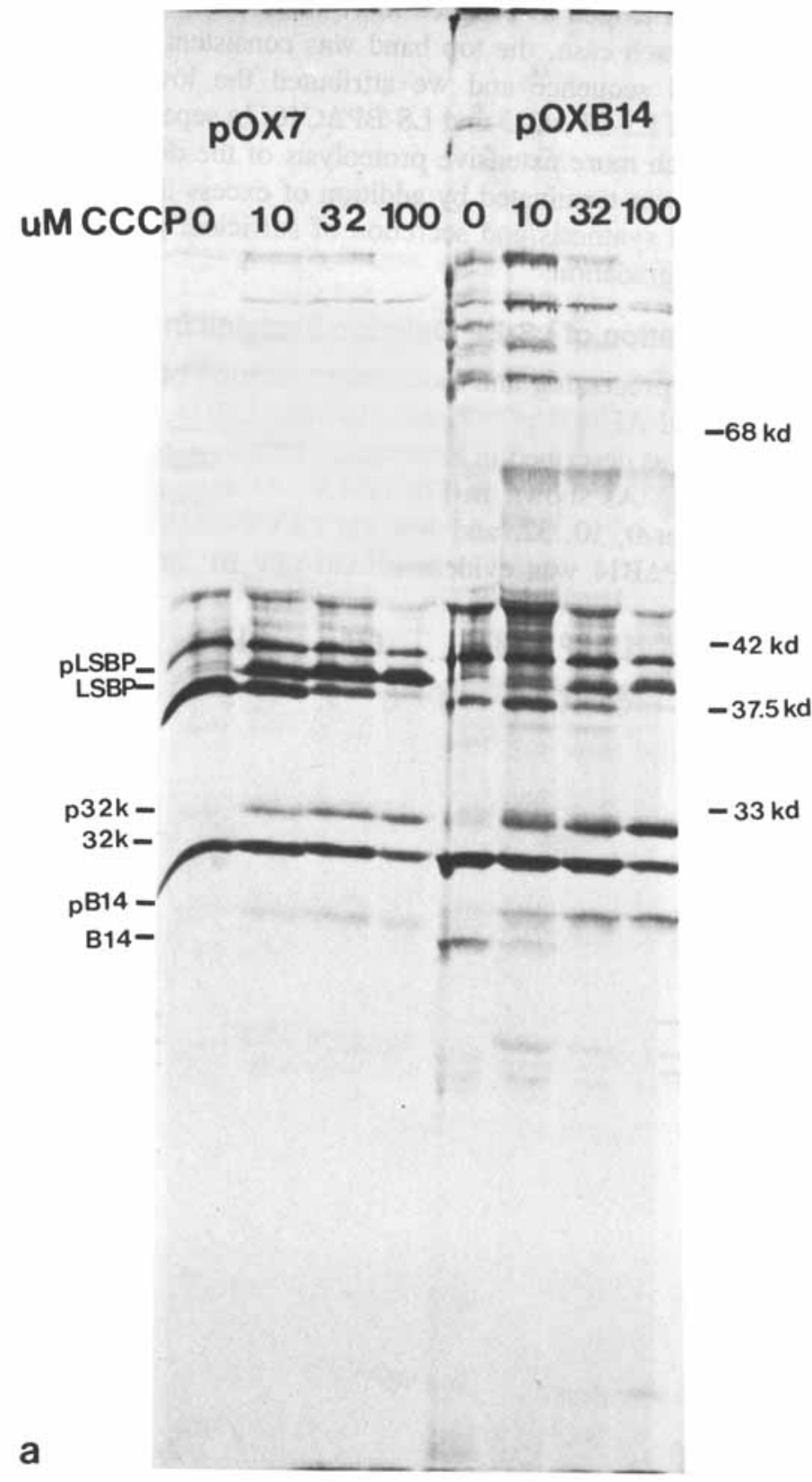

Fig. 4. Synthesis and processing of LS-BPAB14, LS-BP $\Delta C 16$, and LS-BP $\Delta$ G13 in whole cells. Cells of strain AE 404 containing $\mathrm{pOX} 7, \mathrm{pOX} 7 \Delta \mathrm{B} 14$, pOX $7 \Delta \mathrm{C} 16$, or pOX $7 \Delta \mathrm{G} 13$ were grown, labeled, and immunoprecipitated as described in Experimental Procedures and elsewhere [13]. a) AE 404/pOX7 and $\mathrm{AE} 404 / \mathrm{pOX} 7 \triangle \mathrm{B} 14$ were treated with $0,10,32$, or $100 \mu \mathrm{M} \mathrm{CCCP}$ during labeling. The precursor and mature forms of the LS-BP (pLS-BP and LS-BP) and LS-BP $\Delta B 14$ (pB14 and B14) are marked. $\mathrm{p} 32 \mathrm{~K}$ and $32 \mathrm{~K}$ mark the positions of precursor and processed forms of a secretory protein thought to be ompA protein [16] that are insoluble in the $1 \%$ Triton $X-100$ solution used for immunoprecipitation. b) Samples of $\mathrm{AE} 404 / \mathrm{pOX} 7, \mathrm{AE} 404 / \mathrm{pOX} 7 \triangle \mathrm{C} 16$, and pOX7 $\triangle \mathrm{G} 13$ were grown, labeled, and immunoprecipitated as described for a) CCCP was present at either $100 \mu \mathrm{M}$ (+, lanes A, C, and E) or absent (-, lanes B, $\mathrm{D}$, and $\mathrm{F}$ ). 
whole cell proteins radiolabeled with $\left[{ }^{35}\right.$ S]methionine for $30 \mathrm{~min}$. CCCP treatment shifted this band into an apparent precursor form at approximately the same concentrations required to inhibit processing of the $\mathrm{pLS}-\mathrm{BP}$. Figure $4 \mathrm{~B}$ shows results from the same protocol applied to the C16 and G13 deletions. In this case, only 0 - and 100$\mu \mathrm{M}$ CCCP concentrations were used. In Figure $4 \mathrm{~B}$, the bands corresponding to pLS$\mathrm{BP} \triangle \mathrm{C} 16$ and pLS-BP $\Delta \mathrm{G} 13$ are readily apparent in the CCCP-treated cells, but the bands corresponding to the processed forms of these proteins in the untreated cells are almost completely absent (a faint band corresponding to each processed form is visible on the original autoradiograph). We interpreted these results as suggesting that the processed forms of the deletion proteins were probably released into the periplasm where they were rapidly degraded by periplasmic proteases [5]. Closer examination of Figure $4 \mathrm{~A}$ revealed that the processed form of $\mathrm{LS}-\mathrm{BP} \Delta \mathrm{B} 14$ was also present at slightly lower levels than its precursor in equal aliquots of cells. The degradation of LS-BP $\triangle$ B14 is apparently slower than the degradation of LS-BP $\Delta$ C16 and LSBP $\Delta G 13$, perhaps because it contains more of the correct amino acid sequence at its C-terminus. These results demonstrate that processing of all three deleted proteins is detectable.

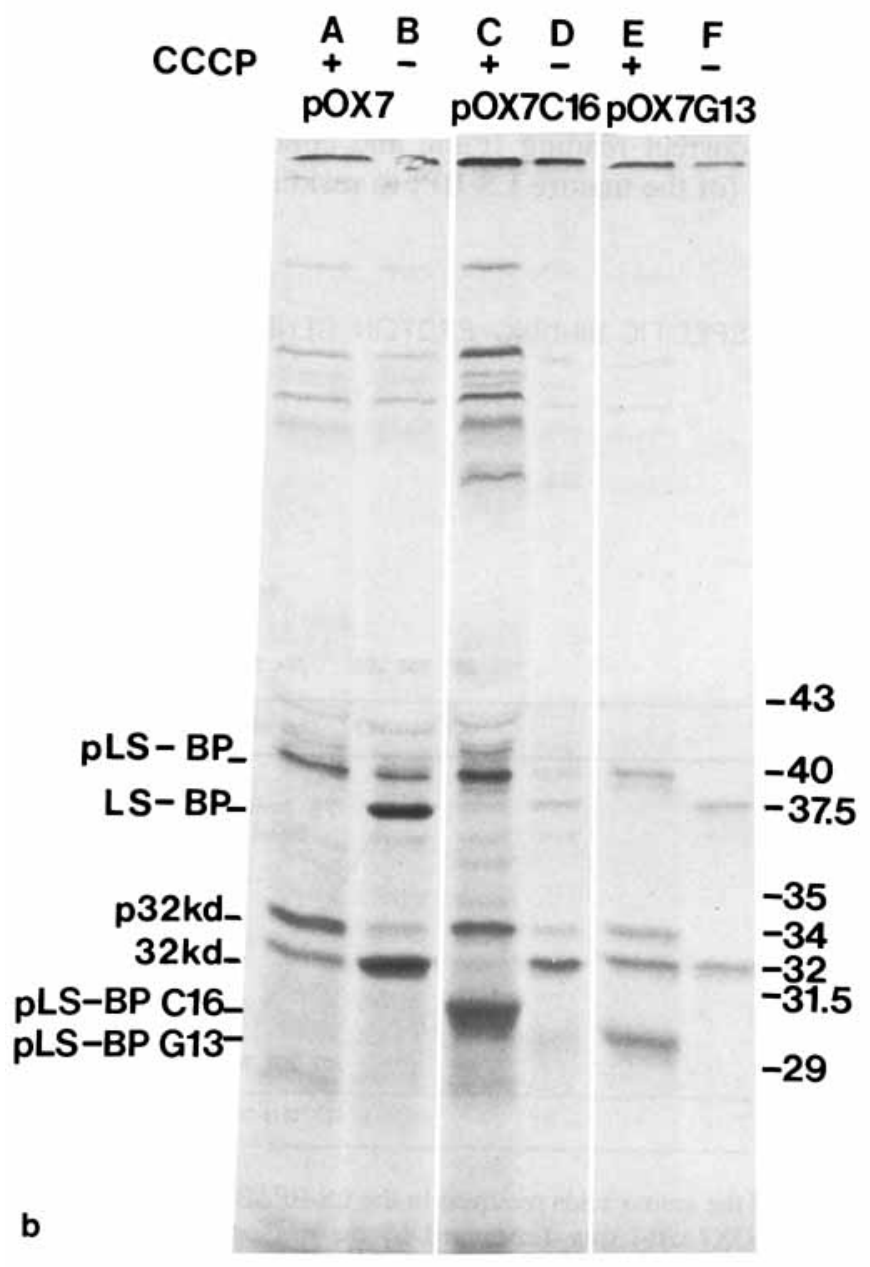

Fig. 4 (continued) 
We also tested to see if LS-BP $\Delta \mathrm{B} 14$ was present in the periplasm of $\mathrm{pOX} 7 \Delta \mathrm{B} 14$ transformed $\mathrm{AE} 404$. We isolated the periplasmic contents of this strain after growth in MOPS-rich medium without leucine by osmotic shock treatment [25] and subjected them to SDS polyacrylamide gel electrophoresis. While AE 404/pOX7 gave a very strong band for the wild-type LS-BP with this protocol, no Coomassie-blue-stainable band corresponding to LS-BP $\triangle B 14$ was evident in the shock fluid from AE 404/ pOX $7 \Delta B 14$ (data not shown). Attempts to detect LIV-BP antisera cross-reacting material in the shock fluid by electrophoretic transfer of the electrophoresed proteins to nitrocellulose and incubation with appropriate antibodies were also unsuccessful. Since the LS-BP $\triangle B 14$ was expressed and secreted in spheroplasts (Fig. 3) and expressed and processed in whole cells (Fig. 4A), we concluded that substantial amounts of the LS-BP $\triangle \mathrm{B} 14$ must have been secreted into the periplasm and then degraded rapidly enough to prevent the accumulation of LS-BP $\triangle B 14$ to any significant steady-state level.

\section{Sequence of the B14 Deletion}

Since only LS-BP $\triangle \mathrm{B} 14$ appeared to retain the correct reading frame, we chose to concentrate on this deletion for further studies. We determined the DNA sequence of the affected portion of the LS-BP $\triangle \mathrm{B} 14$ gene by conventional methods [21]. Figure 5 shows the results of the DNA sequencing experiment. LS-BP $\triangle B 14$ was fused so that it maintained the correct reading frame and contained a deletion of 78 amino acids from residue 234 (of the mature LS-BP) to residue 312 .

\section{LEUCINE-SPECIFIC BINDING PROTEIN GENE}

WILD TYPE

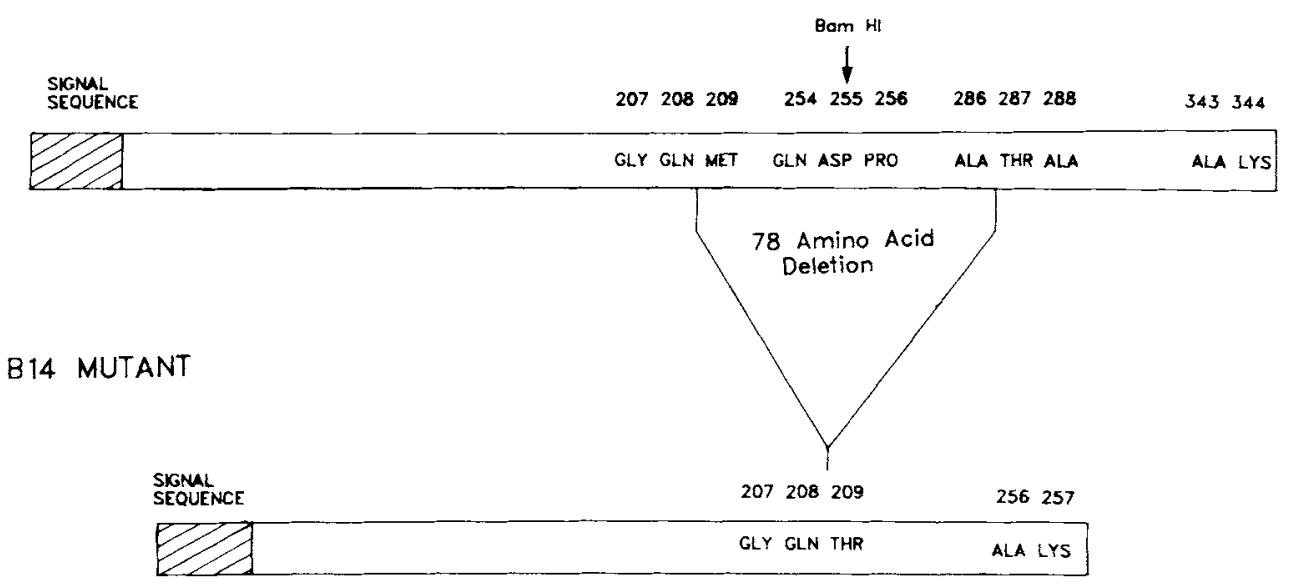

Fig. 5. Exact location of the amino acids removed in the LS-BP $\triangle B 14$ deletion. The DNA sequence of the relevant portion of pOX $7 \Delta B 14$ was determined by the method of Maxam and Gilbert [21] and compared to the known sequence of the LS-BP gene [Landick and Oxender, in preparation] to precisely map the deletion as shown. 


\section{Degradation of LS-BP $\triangle B 14$ by Periplasmic Proteases}

As a final test of the hypothesis that the LS-BPAB14 was degraded by periplasmic proteases, we examined the stability of partially purified LS-BP $\Delta B 14$ when it was incubated with osmotic shock fluid proteins in vitro. Osmotic shock fluid was isolated from strain $\mathrm{AE} 84$ (as $\mathrm{AE} 404$ but recA $^{+}$livH ${ }^{+}$thyA) by the method of Neu and Heppel [25]. LS-BP $\triangle B 14$ was labeled with $\left[{ }^{35}\right.$ S]methionine in spheroplasts of $A E 404 / p O X 7 \triangle B 14$. After removal of the spheroplasts by centrifugation and filtration through Sephadex G-25, the ${ }^{35}$ S]methionine-labeled LS-BP $\Delta$ B14 was divided into aliquots and incubated with increasing concentrations of osmotic shock fluid protein. As shown in Figure 6, at concentrations of osmotic shock fluid protein above $50 \mu \mathrm{g} /$ $\mathrm{ml}$ the LS-BP $\Delta \mathrm{B} 14$ was degraded in $15 \mathrm{~min}$ at $37^{\circ} \mathrm{C}$ while the wild-type LS-BP was left intact. From these results we concluded that removal of the 78 amino acids missing in LS-BP $\triangle \mathrm{B} 14$ caused the deleted protein to become susceptible to degradation by periplasmic proteases while the wild-type LS-BP is resistant to attack. We infer from this that LS-BP $\triangle B 14$ must fold into a conformation that renders the deleted protein susceptible to attack; all of the amino acid sequences present in LS-BP $\triangle B 14$ are present in the LS-BP and, therefore, the primary sequence of LS-BP $\Delta B 14$ alone must not be recognized by the periplasmic proteases.

\section{DISCUSSION}

In this report we have described the construction of C-terminal deletions in the E coli LS-BP gene and studied the secretion, processing, and periplasmic degradation of the deleted proteins coded for by these genes. We have extensively characterized one of these deletion proteins, LS-BP $\triangle B 14$, by determining that 78 amino acid residues, from amino acid 234 to residue 312, are missing in this deletion. We have reasoned that the other two deletion proteins, LS-BP $\Delta$ C16 and LS-BP $\Delta$ G13, contain missense amino acid sequences at their $\mathrm{C}$-termini. We have examined the secretion and processing of the deletion proteins in whole cells and spheroplasts and we have specifically tested the susceptibility of LS-BP $\Delta \mathrm{B} 14$ to degradation by periplasmic proteases.

Five important conclusions can be drawn from this study:

(1) Significant portions of the C-terminal amino acid sequences in the LS-BP are not required for processing and secretion of the protein into the periplasm.

(2) LS-BP molecules containing C-terminal deletions are degraded by periplasmic proteases.

(3) Altered conformation, and not a specific sequence, determines the susceptibility of the deleted proteins to periplasmic protease degradation.

(4) LS-BP deletions that contain missense amino acid sequences at their C-termini are more rapidly degraded than the LS-BP $\Delta \mathrm{B} 14$ deletion which contains an internal deletion.

(5) CCCP inhibition of secretory protein processing can be used to detect synthesis of otherwise unstable periplasmic proteins.

Randall [30] has observed that processing of the maltose-binding protein is not initiated until $80 \%$ of the polypeptide chain has been synthesized [30]. These findings have been interpreted as showing that a certain minimum length of the $\mathrm{N}$-terminal region of a secretory protein is required for protein processing and secretion. In this report, the results suggest that the critical $\mathrm{N}$-terminal region of the LS-BP must be 234 amino acids or less. 


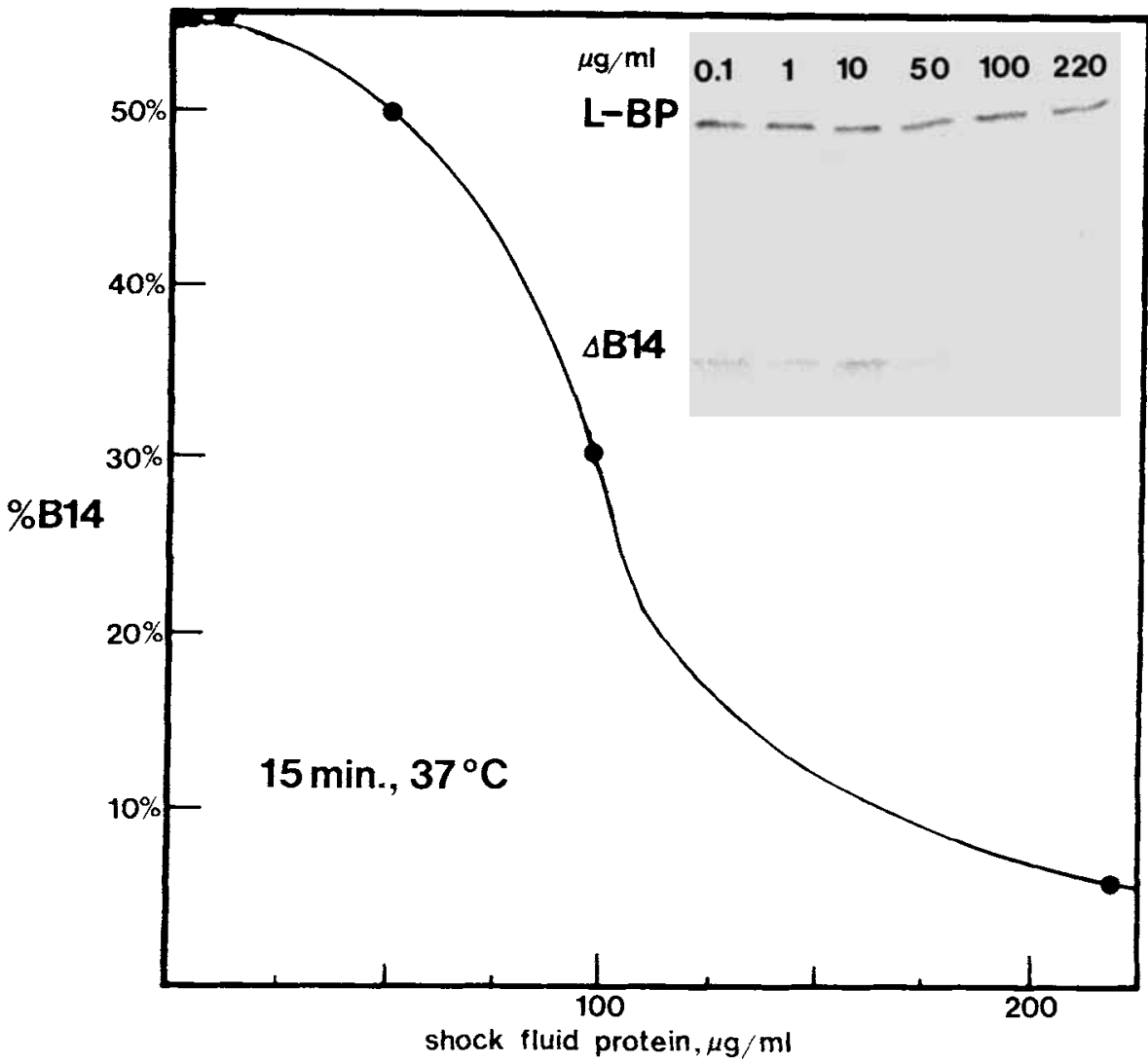

Fig. 6. Degradation of partially purified LS-BP $\Delta B 14$ by osmotic shock fluid protein. Secreted proteins from $A E 404 / p O X 7 \triangle B 14$ were isolated from the labeling medium of spheroplasts prepared and labeled as described in Experimental Procedures. The isolated labeling medium, after removal of spheroplasts by centrifugation, was loaded on a Sephadex G-25 column equilibrated with $10 \mathrm{mM} \mathrm{KPO}, \mathrm{pH} 6$, and the labeled secretory proteins were recovered in the same buffer from the void volume fractions. Osmotic shock fluid was prepared from strain AE 84 by conventional methods [27]. Fractions of the labeled secretory proteins were incubated at $37^{\circ} \mathrm{C}$ for $15 \mathrm{~min}$ in the presence of the indicated concentrations of osmotic shock fluid protein. The fractions were then immunoprecipitated as previously described [13] and electrophoresed through an $11 \%$ polyacrylamide SDS gel. After electrophoresis, the bands corresponding to the LS-BP $\triangle B 14$ and the mixture of LS-BP and LIV-BP (labeled L-BP) were located by autoradiography (shown in the insert), cut from the gel, and counted in liquid scintillation fluid. The percentage of remaining LS-BP $\triangle \mathrm{B} 14$ relative to the total LIV-BP, LS-BP, and LS-BP $\triangle \mathrm{B} 14$ was calculated without correction for the number of methionine residues in each protein and is plotted against the concentration of osmotic shock fluid protein present during the $37^{\circ} \mathrm{C}$ incubation.

The observed degradation of the LS-BP deletions has important implications for the study of protein secretion in E coli. The ease with which the altered LS-BP molecules are degraded by periplasmic proteases suggests that analysis of proteins that are present may be an inadequate assay for the secretion of a given protein. Proteins not ordinarily found in the periplasmic space may be sensitive to proteolytic degradation while periplasmic proteins, such as the LS-BP, are not degraded by a variety of proteases even though they contain sequences normally hydrolyzed by these 
proteases [16]. Apparently, secretory proteins fold into conformations that protect them from proteolytic degradation. Much experimental effort is currently being directed at determining the structural requirements for protein secretion. Frequently, these experiments involve construction of fused protein molecules with signal sequences from secreted proteins and altered or nonsecretory protein sequences in the mature portion of a protein. Appearance of these proteins in the periplasmic space as assayed by osmotic shock treatment [25] or release after lysozyme-EDTA treatment has been used as criteria for successful protein secretion. These criteria were used initially to conclude that a $\beta$-lactamase missing a small portion of its $C$-terminus was not secreted [26] although later work involving lysozyme and EDTA treatment and trypsin accessibility showed that the protein in question was secreted [27]. We were able to show that the spheroplast assay shown in Figure 3 and described elsewhere [13] was a reliable test of protein secretion, but even here, one should be aware of possible proteolysis of the secreted proteins (see Fig. 3 and Results).

Degradation of secretory proteins by periplasmic proteases is equally important for current efforts to design proteins that can be synthesized and secreted in E coli or other bacteria in sufficient quantity to simplify large-scale purification. While some of these efforts have already been successful, most notably for insulin [28], most of these have been directed at small proteins that are normally secreted in other organisms. As these schemes are expanded to include larger proteins and proteins that are not ordinarily secreted, the issue of proteolytic degradation may become more important.

The LS-BP C-terminal deletions described in this report may be useful in characterizing periplasmic proteases and in constructing mutant strains in which their activities are reduced or eliminated. It is already known that more than one periplasmic protease is present in $\mathrm{E}$ coli [5]. It will be important to determine if only one of these activities is responsible for the observed degradation of the LS-BP deletions. It may be possible to use altered secretory proteins such as the LS-BP deletions to screen mutant strains for loss of the periplasmic proteases.

\section{ACKNOWLEDGMENTS}

This work was supported in part by grant GM 11024 from the National Institutes of Health. B. Copeland held an Arthur F. Thurnau fellowship and P. Nazos was supported by a fellowship from the American Association of University Women.

\section{REFERENCES}

1. Quay SC, Oxender DL: NY Acad Sci 264:358, 1976.

2. Landick R, Oxender DL: In Martonosi A (ed): "Membranes and Transport: A Critical Review." New York: Plenum Press, 1982, pp 81-91.

3. Furlong CE, Schellenberg GD: In Payne JW (ed): "Mircroorganisms and Nitrogen Sources." New York: J.W. Wiley, 1980, pp 89-123.

4. Landick R, Oxender DL, Ames GF-L: In Martonosi A (ed): "The Enzymes of Biological Membranes," 2nd Edition. New York: Plenum Press (in press).

5. Sveedhara Swamy KH, Goldberg AL: J Bacteriol 149:1027, 1982.

6. Inouye $\mathrm{H}$, Barnes $W$, Beckwith $J$ : J Bacteriol 149:434, 1982.

7. Michaelis S, Beckwith J: Annu Rev Microbiol 36:435, 1982.

8. Wolf PB, Silver P, Wickner W: J Biol Chem 257:7898, 1982. 


\section{4:JCB Landick et al}

9. Zwizinski C, Date T, Wickner W: J Biol Chem 256:3593, 1981.

10. Daniels CJ, Bole DG, Quay SC, Oxender DL: Proc Natl Acad Sci USA 79:5396, 1981.

11. Enequist HG, Hirst TR, Harayama S, Hardy SIS, Randall LL: Eur I. Biochem 116:227, 1981.

12. Date T, Zwizinski C, Ludmerer S, Wickner W: Proc Natl Acad Sci USA 77:827, 1980.

13. Landick R, Daniels CJ, Oxender DL: Methods Enzymol 97:146, 1983.

14. Oxender DL, Anderson JJ, Daniels CJ, Landick R, Gunsalus RP, Zurawski G, Yanofsky C: Proc Natl Acad Sci USA 77:1412, 1980.

15. Landick R, Anderson JJ, Mayo MM, Mavromara P, Gunsalus RP, Daniels CJ, Oxender DL: I Supramol Struct 14:527, 1981 .

16. Oxender DL, Anderson JJ, Daniels CJ, Landick R, Gunsalus RP, Zurawski G, Yanofsky C: Proc Natl Acad Sci USA 77:2005, 1980

17. Gray HB, Winson TP, Hodnett JL, Legerski RJ, Nees DW, Wei C, Robberson DL: In Chirikjian TS and Papas JG (eds): "Gene Amplification and Analysis." Amsterdam: Elsevier Press, 1981, pp 169-203.

18. Anderson JJ, Oxender DL: J Bacteriol 130:384, 1977.

19. Clewell DB, Helinski DR: Proc Natl Acad Sci USA 62:1159, 1969.

20. Bahl CP, Marians KJ, Wu R, Stawinsky J, Narang SA: Gene 1:81, 1976.

21. Maxam AM, Gilbert W: Methods Enzymol 65:499, 1980.

22. Neidhardt FC, Block PL, Smith DF: J Bacteriol 119:736, 1974.

23. Daniels CJ: Ph.D. Thesis "Synthesis and Processing of the Periplasmic Leucine Transport Proteins of Escherichia Coli," University of Michigan, Ann Arbor, Michigan, 1981.

24. Laemmli UK: Nature 227:680, 1970.

25. Neu HC, Heppel LA: J Biol Chem 240:3685, 1965.

26. Koshland D, Botstein D: Cell 20:749, 1980.

27. Koshland D, Botstein D: Cell 30:893, 1982.

28. Talmadge K, Stahi S, Gilbert W: Proc Natl Acad Sci USA 77:3369, 1980.

29. Sutcliffe JG: Cold Spring Harbor Symp Quant Biol 43:77, 1979.

30. Randall LL: Cell 33:231, 1983. 